\title{
Exploring the meaning of social innovation: a categorisation scheme based on the level of policy intervention, profit orientation and geographical scale
}

\section{Nuno Baptista, João Pereira, António Carrizo Moreira \& Nelson De Matos}

To cite this article: Nuno Baptista, João Pereira, António Carrizo Moreira \& Nelson De Matos (2019) Exploring the meaning of social innovation: a categorisation scheme based on the level of policy intervention, profit orientation and geographical scale, Innovation, 21:3, 379-397, DOI: 10.1080/14479338.2019.1585188

To link to this article: https://doi.org/10.1080/14479338.2019.1585188

央 Published online: 05 Mar 2019.

Submit your article to this journal $₫$

山 Article views: 353

Q View related articles $\longleftarrow$

View Crossmark data ¿`

Citing articles: 4 View citing articles 


\title{
Exploring the meaning of social innovation: a categorisation scheme based on the level of policy intervention, profit orientation and geographical scale
}

\author{
Nuno Baptista (iD ${ }^{a}$, João Pereira ${ }^{b}$, António Carrizo Moreira (D) $^{c}$ and Nelson De Matos ${ }^{d}$ \\ aEscola Superior de Comunicação Social, Lisbon, NECE-UBI - Covilhã, Portugal, Instituto Politécnico de

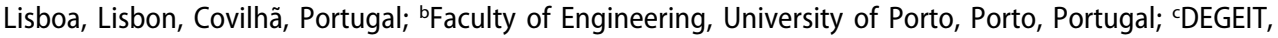

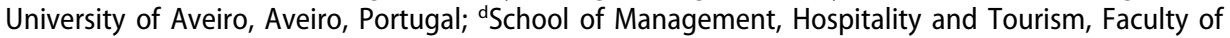 \\ Economics, University of Algarve, Faro, Portugal
}

\begin{abstract}
There has been a growing interest in academia regarding the term 'social innovation', including in disciplines such as sociology, administration, history, management, psychology, and economics. The literature highlights the lack of scientific clarity in the use of the term, and some scholars argue that the term is no more than a 'buzzword' or a 'fad'. This article focusses on the analysis of the conceptualizations of social innovation, contrasting sociological and economical approaches, and adopts an integrative approach to propose a categorization scheme of social innovation projects based on three distinct variables, namely the level of policy support, the profit orientation and the geographical scale. We argue that government support and the scalability of social innovations should be carefully pondered depending on the characteristics of the social innovation initiatives. We conclude that policy support should privilege social innovation initiatives that, while having the potential to deliver social good, are constrained by market failures. In addition, we also argue in favour of policy support for small bottom-up initiatives that have a profit-logic but are not sufficiently robust to survive on their own due to the liabilities of smallness and newness. Finally, we advise caution in public policies supporting scale-up strategies and highlighted the inherent challenges.
\end{abstract}

\section{ARTICLE HISTORY}

Received 29 January 2019

Accepted 12 February 2019

\section{KEYWORDS}

Social innovation; policy intervention; profit orientation; geographical scale

\section{Introduction}

The term 'social innovation' emerged from the francophone academy in the 1970s (Rana, Weerakkody, Dwivedi, \& Piercy, 2014) and has since been the focus of increasing interest in various social sciences, including sociology, administration, history, management, psychology and economics (Cajaiba-Santana, 2014; Van der Have \& Rubalcaba, 2016). Mostly building on previous research on innovation, a significant quantity of definitions of social innovation have been proposed. In a recent systematic review that included grey and academic literatures, Edwards-Schachter and Wallace (2015) were able to identify as many as 252 definitions of social innovation and argued that, despite the quantity of definitions proposed, it is still not easy to answer the 
question of what social innovation is. Described as a 'buzzword' by Pol and Ville (2009), social innovation has become 'overdetermined', lacks scientific clarity (EdwardsSchachter \& Wallace, 2015) and the state of knowledge continues to be fragmented (Dawson \& Daniel, 2010) without unifying paradigms (Cajaiba-Santana, 2014). The present disintegrated state of research complicates the systematic accumulation of knowledge and the growth of social innovation as a research field (Van der Have \& Rubalcaba, 2016).

Sociological grounded conceptualisations understand social innovation as new ways of creating and implementing social change. The conceptual focus tends to be on social practices and on the ways in which they can be combined. This approach considers social innovation as a new innovation paradigm rather than a separate category of innovation. Under this line of thought, Cajaiba-Santana (2014, p. 44) considers social innovation as 'new ideas manifested in social actions leading to social change and proposing new alternatives and new social practices for social groups'.

On the other side, economic conceptualisations of social innovation are more outcome-oriented and related to the 'ideas', 'services' or new 'systemic' transformations and their related social impacts (Van der Have \& Rubalcaba, 2016). Under this framework, and focused on the outcome of social innovations, Pol and Ville (2009) consider innovations as desired social innovations when the implied outputs can either improve the macro-quality or the quantity of life.

While previous research on the plurality of definitions of social innovation appears not to have solved the perceived ambiguity surrounding the concept (Van der Have \& Rubalcaba, 2016), and considering the fragmentation problem of the field, this article focuses on the analysis of the conceptualisations of social innovation proposed by Pol and Ville (2009) and Cajaiba-Santana (2014) by presenting an analysis of the two influential articles contributed by these authors. In addition, and with the objective of characterising social innovations and the importance of supporting public policy, we propose a tri-dimensional categorisation of social innovations based on the following variables: the level of policy intervention, the profit orientation and the geographical scale.

The contributions of this study are twofold. First, it provides a critical overview of two fundamental articles that reflect the main streams of the economic and sociological views of the concept of social innovation. Second, drawing on these two key articles and additional literature, an integrative approach is adopted to present a categorisation scheme of social innovations as an instrument to reflect upon public policies that can be practically used by policy makers, government agents, public managers and funding bodies.

The main conclusions of this study are reflected in the dimensions of the proposed model. It is suggested that policy efforts should privilege the support of social innovation initiatives that, while having the potential to promote social good, are constrained by market failures. The model also argues in favour of government support for new small bottom-up initiatives that, while having a profit-driven logic, are not sufficiently robust to survive on their own due to being in their introductory stage. Finally, caution is advised in public policies supporting scale-up strategies. 


\section{A sociological and an economic perspective on social innovation}

Cajaiba-Santana's (2014) framework of social innovation considers an individual and a structural perspective of social innovation whose combination the author denominates as the 'structuration perspective'. In the individualistic view, agents' values and attributes are the primary causal forces determining social innovation. Social innovation is, in this perspective, the result of the action of visionary individuals who can find innovative solutions to social problems that are not adequately met by the existing system. Conversely, the structural view implies that structure and context will affect innovation. The structuration perspective is conceived as interactively influenced by both agents and social structures and is rationalised based on institutional theory and structuration theory.

Cajaiba-Santana employs institutional theory to argue that social innovation is always related to collective social action aiming at social change. The institutional perspective understands social innovation as resulting from the exchanges and application of knowledge and resources by agents who are mobilised through legitimisation activities. Second, Cajaiba-Santana uses structuration theory to describe how social innovation is generated through the relationships between agents, institutional structures and social systems.

In the sociological inspired framework proposed by Cajaiba-Santana (Figure 1), agents actively and reflexively interact with their social contexts, transforming and being transformed by it, as they promote social change through social innovation. Innovation agents are simultaneously constrained and enabled by structures (or institutions) to (re)create social systems. Communicative actions are directed by agents

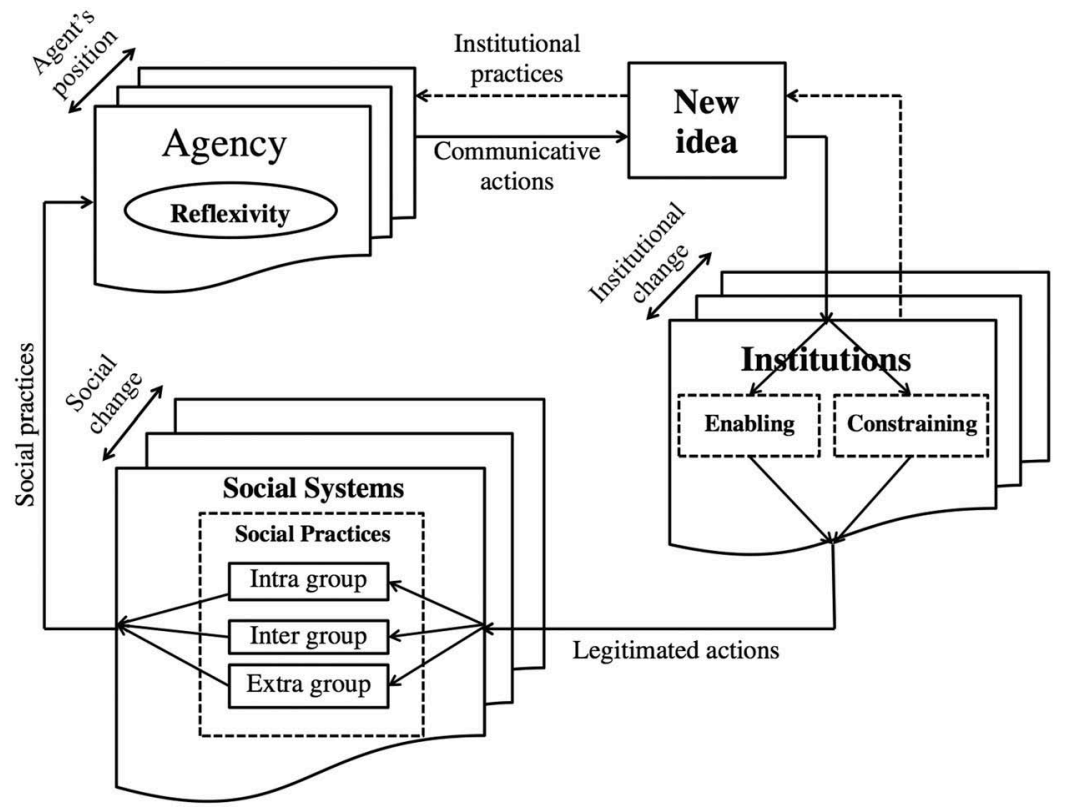

Figure 1. Cajaiba-Santana's conceptual model.

Source: Cajaiba-Santana (2014) 
towards the achievement of a mutual understanding among individuals who are interacting to coordinate their actions based on the collective interpretations of the social context. It is legitimacy that gives validity to the actions that change social systems and create new and legitimised social practices.

Finally, Cajaiba-Santana's model implies three differentiated levels of social innovation. First, there are the intra-group innovations. The institutions that frame the actions at this level are within the group and the innovations can relate to the basic norms, values, rules, habits and conventions of a given social group. Next, the author identifies the level of inter-group social innovations. At this level, different social groups are linked in collaborative and/or competitive relationships. The third level consists of a macro level of social systems or extra-group social innovations.

Pol and Ville (2009) argue that social innovation is a concept that is urgently in need of theoretical refinement. Based on an extensive review of the extant conceptualisations, Pol and Ville propose a very simple and encompassing definition of social innovation. They assert that an innovation is a desirable social innovation if the implied new idea has the potential to improve either the macro-quality or the quantity of life.

It is important to note some relevant features in Pol and Ville's social innovation concept. First, for a specific innovation to be a social innovation, it must be desirable. As history shows, not all innovations are desirable since they can have non-negligible negative impacts on health (e.g., cigarettes), on the environment (e.g., car pollution) or on the distribution of wealth (e.g., robots). Second, the innovation must impact the quantity of life (longevity) or the macro-quality of life, given the set of valuable options that citizens can select (e.g., material well-being, education opportunities, health, job security, family life, political freedom, etc.).

Pol and Ville claim that, while distinctive, there is substantial intersection between the set of business innovations and the set of social innovations since the former can have a relevant social impact (Figure 2). In this sense, innovations can be bifocal (e.g.,

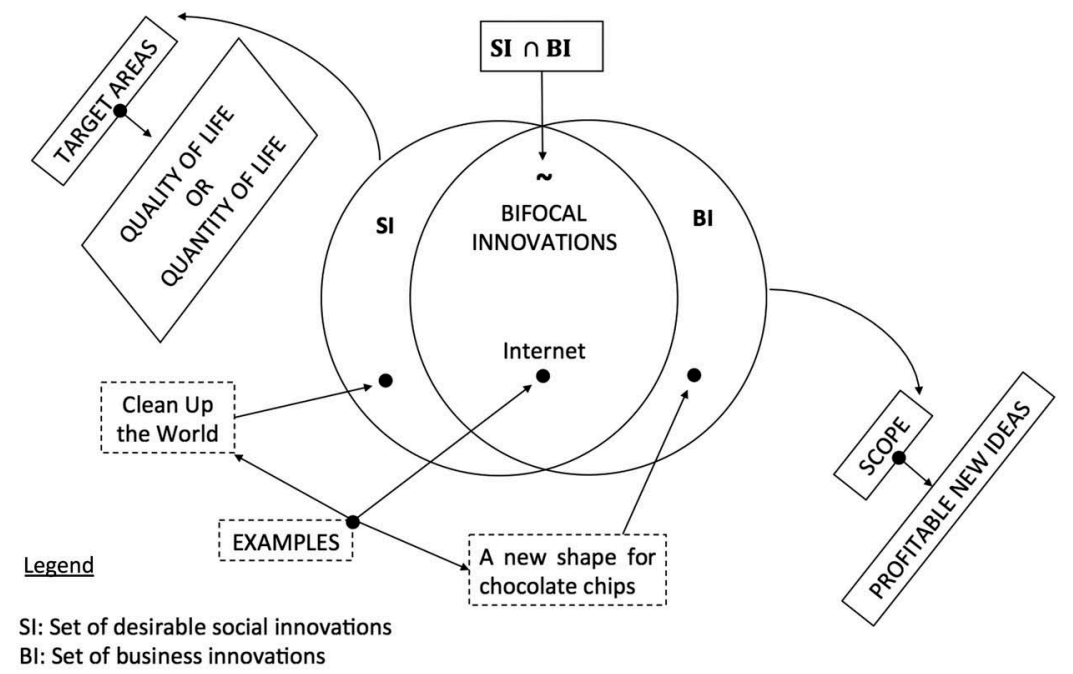

Figure 2. Social innovation and business innovation relationship.

Source: Pol and Ville (2009) 
internet), purely social innovations (e.g., Clean Up the World initiatives) or purely business innovations (e.g., a new shape for chocolate chips).

Finally, Pol and Ville argue that there is a subset of social innovations that can be subject to market failures and face under-investment due to a lack of material incentives. These pure social innovations show the central features of public goods: it is not possible to exclude others from the benefits of the new idea, and the marginal cost of an additional person using the new idea is zero. Consequently, the argument is that there are weighty reasons to justify government intervention for pure social innovations.

\section{A critical analysis of the two frameworks}

The essence of the sociological model proposed by Cajaiba-Santana rests in the principle that social innovation analysis must focus on the relationships between agents and social systems, and, because of that, structuration and institutional theories are particularly useful to understand the nature of the social innovation process. Conversely, Pol and Ville appeal to socioeconomics, innovation and public economics to develop an output-oriented concept of social innovation that identifies 'improving the macroquality or quantity of life' as the desirable outcomes of social innovation.

Cajaiba-Santana disagrees with the social innovation approaches that consider the concept as a simple normative instrument targeting social problems. To the author, this kind of instrumental definition generates a too narrow view of social innovation for three reasons. First, an answer to a social problem is not necessarily a social innovation; even technical innovations are aimed at solving social problems. Second, this view proposes a material dimension of social innovation (as a product) that is incoherent with the ontological immateriality of the phenomenon. Finally, for the author, social innovation is about social change, and this should be the main characteristic to be proven.

Contrary to Cajaiba-Santana, Pol and Ville highlight a grey border between business and social innovation and consider that 'bifocal innovations' can share the characteristics of both business and social innovations. They do not advance, though, a clear initial definition of what they understand as 'innovation', and the specific characteristics that support each of the identified sets of business and social innovations need clarification. On the other hand, the authors consider that social innovations must be desirable and target the macro-quality of life and these are difficult notions to be operationalised.

Cajaiba-Santana's model presents a new understanding on the processes within social innovation by stressing the roles of both agents and social structures. However, the author recognises that the model does not have the pretention of unifying the field of social innovation around one single paradigm, as attempted by Pol and Ville. In fact, we found Cajaiba-Santana's model to lack the relevant dimensions of social innovation, most notably the antecedents that may force or favour social innovation processes and the outcomes of social innovation. 


\section{A tri-dimensional categorisation scheme of social innovation}

Agency is a crucial tenet of structuration theory that considers actors to be purposeful, knowledgeable and reflexive. The idea of 'reflexivity' assumes an important role in Cajaiba-Santana's model and implies that actors have the capacity to routinely monitor their actions by reflecting upon them and acting in line with their intentions. Within this context, reflexivity stands for the continuous monitoring of the social context and the activities taking place within this context by the agents.

Continuous monitoring requires a reflexive process of analysis of innovation outcomes, and this necessarily involves the evaluation of social innovation projects' economic sustainability in the long run. This also implies that outputs do matter and that governments, as relevant actors in the process of social innovation, must be able to access and ponder their level of support for specific social innovation projects. Pol and Ville recognise that there is a subset of social innovations that can be subject to market failures and that there are strong arguments for governments to support these types of projects.

Cajaiba-Santana's model identifies three differentiated levels of social innovation: intra-group, inter-group and extra-group social innovations. Research on the extragroup social innovation involves the analysis of a macro level of social systems, including the study of public policies. According to the author, this level of analysis has received little attention in previous studies.

Based on the arguments presented by both authors, and with the objective of characterising social innovations, from a macro level perspective, we resort to a tridimensional matrix representation that explores the interrelationships between the following key variables: i) the level of policy intervention, which relates to the level of government intervention or support for the social innovation initiative; ii) the profit orientation, reflecting the level of intensity of the profit orientation; and iii) the geographical scale, referring to the capacity of social innovations to be scaled up geographically. Next, we present each variable that is included in the model.

\section{Policy intervention}

Competitive markets are inefficient (they fail) if they exhibit characteristics such as externalities from public goods, increasing returns or imperfect information. As a consequence, some activities will be underprovided in the market since rational agents cannot capture those external benefits, or they face moral hazard and adverse selection incentives, because the resulting distribution of income and wealth is inequitable (Le Grand, 1991; Tamm, 2010). This means that policy intervention by the government, such as through a combination of providing products and services, taxing or funding, and regulating, can be used in the presence of the aforementioned market failures.

Le Grand (1991) argues that government failures vary with the type of policy intervention, and can result in limited or absent policy intervention. In the case of the government provision of products and services, when they are a monopoly or facing competition from nonprofit organisations, cost efficiency incentives can be absent. In the case of the funding of activities and organisations, excessive or under-provision can 
prevail, even in the presence of a rational decision process delegated to self-interested government bureaucrats and employees or even independent professionals. Finally, in the case of regulation, a perfectly informed, motivated and independent regulator would be needed.

The literature also points to the fact that governments may not have the knowledge or capabilities that are needed to develop an adequate policy intervention (Tamm, 2010) or they may face difficulties when serving social minority groups that deviate from the norm since public sector organisations typically serve in a very standardised and universal way (Borzaga \& Bodini, 2014), and often governments focus on the policy intervention in specific organisations, innovation stages or pilot projects, thereby limiting the impact and efficiency by not permitting the replication and scaling up (Adams \& Hess, 2010).

Adding to the discussion, Van der Have and Rubalcaba (2016), seeing the merit in active policy intervention in the face of market failures, such as the support of nonprofit organisations, argue that more elaboration must be given for another group of failures, systems failures, that can deter social innovations. As an example, the authors refer to a potential lack of interaction between the government and agents that can hinder the scalability of successful social innovations in local communities. In this sense, policy intervention can be justified not only by market failures but also by systemic failures (Tamm, 2010). Weber and Rohracher (2012) offer an overview of these new types of failures, dividing them into structural system failures (e.g., infrastructural, institutional, interaction or network, and capabilities failures) and transformational system failures (directionality, demand articulation, policy coordination and reflexivity failures).

In the absence of or decreasing policy intervention, such as in the case of the modern welfare systems, where governments are facing growing difficulties and even retreating (e.g., budget constraints), specialised policy intervention addressing social innovations should focus not only on social enterprises but also on public-private partnerships that, by involving the public and private sectors, can bring both desirable effectiveness and efficiency to scalable social innovation (Borzaga \& Bodini, 2014; Nicholls \& Murdock, 2012). The support of these new organisations seems promising, and policy intervention can develop through different levels of intensity, ranging from simple subsidies and contracting policies to the proper regulation of the activity - e.g., uniform regulations, removing implicit barriers, adapting accounting and fiscal rules, and developing public procurement rules (Borzaga \& Bodini, 2014). We adopt these holistic approaches to failures that demand (or are bounded by) different levels of policy intervention.

\section{Profit orientation}

Some literature establishes a distinction between economic and social innovation based on the dichotomy of the profit versus nonprofit orientation (Cajaiba-Santana, 2014; Gregoire, 2016). Cajaiba-Santana (2014) considers that Schumpeter's conceptualisation of innovation, which was adopted by management and technological literatures, understands innovation as a source of economic value creation and considers profitability and commercial success as key drivers for innovation. According to this author, social innovation aims at social change, and this implies a different approach that cannot be established on the basis of profit maximisation. In a similar view, Gregoire (2016) 
considers the centrality of the social dimension and the ambition of social transformation to be the distinctive elements of social innovation that differentiate it from economic innovation, whose main purpose, according to the author, is profit maximisation or cost reductions. Gregoire (2016) recognises, however, that there is a blurred border between economic and social innovation because some economic innovations may lead to other innovations in which the social dimension becomes central (e.g., open-source software).

An emerging view in the social innovation literature is that the creation of economic and social value is not necessarily at odds with each other (Dembek, Singh, \& Bhakoo, 2016; Păunescu, 2014; Van der Have \& Rubalcaba, 2016). The value created by means of the introduction of new products, services or processes is often not fully captured by the innovating firm because of the positive spillovers to society (Van der Have \& Rubalcaba, 2016). This implies that innovations create shared value (economic and social) to be shared between the involved participants (Păunescu, 2014).

In this article, we follow Van der Have and Rubalcaba's (2016) approach by considering that it is possible to establish a distinction between the different types of social innovations depending on the intensity of the profit orientation. In the lower spectrum, we have the pure social innovations, which deliver social value, and aim to satisfy social needs that are not possible to fulfil through the market. At the higher level of the continuum, we have 'bifocal' social innovations, which are the ones that generate positive social value and are still a business innovation in the sense that there is a monetary value in exchange, and the innovator appropriates economic value.

\section{Geographical scale of social innovations}

The different conceptualisations of social innovation that emerged in the literature tend to imply differentiated scales of analysis. A historical analysis of the literature on social innovation conducted by Neumeier (2012) identifies three distinct approaches to social innovation: an economics-based approach, a first sociological-based approach and a second sociological-based approach.

The economic approach is based on the work of Schumpeter (1949) and consists of an organisation-centred perspective in which social innovations are understood as new ways of organising business practices, the workplace or the external relations of an enterprise. We consider this approach to be more easily identified with a micro level of analysis were the focus of action tends to be on the organisations and the employees.

In the first sociological approach, social innovations are considered as societal achievements that affect the direction of social change and that provide improved solutions compared to already established solutions in order to meet one or more common goals to help create better futures for society. In our view, this line of thinking can be mostly related to a macro level of analysis where social innovation is conceived as an instrument to improve society in general.

The second sociological approach accentuates the potentiality of innovation to foster change in the common goals of a specific group of people. In this case, social innovations are seen as the generation and implementation of new ideas on how individuals may organise interpersonal activities or social interactions in order to meet one or more common goals. According to Neumeier (2012), the objectives of social innovation in 
this perspective are not societal goals but are the improvements in things such as the acting, organisation and know-how of a group of people. We consider this perspective to also be related to a micro level of analysis where social innovation is conceptualised in the context of small groups of individuals focusing on how they should organise interpersonal activities or social interactions in order to meet one or more of their common goals.

In a recent systematic literature review conducted by Van der Have and Rubalcaba (2016), the authors highlight how specific scholarly communities tend to focus on certain levels of social innovation. Some scholars whom the authors classify as being in the 'social and societal challenges' scholar community are mostly focused on social innovation as a tool to solve large-scale problems, such as the sustainability of the climate, environment and health provisions. Other scholars who are classified as being in the 'local development' community are mostly focused on the role of social innovation in local development, including communities or neighbourhoods, cities and regions, and both urban and rural settings.

Social innovations can either target a social problem that relates to a limited group of individuals or focus on deep structural problems that affect a large number of individuals and involve large-scale impacts (Păunescu, 2014). This assertion implies that social innovations can be situated on a scale depending on the dimensions of the people who benefit from the innovation. Social innovations can impact the micro, meso or macro levels of society (Furmanska-Maruszak \& Sudolska, 2016) and can be escalated.

Not all social innovations are predestined to be scaled up by simply reproducing successful solutions at the local level; some should adapt the solutions, and others should even maintain their local operations without any concern for growth (Westley, Antadze, Riddell, Robinson, \& Geobey, 2014). For example, Hiteva and Sovacool (2017) discuss four companies/projects that are involved in social innovation at different scales (local, subnational, regional and global) in the energy sector. Considering that the drivers for energy justice are localised and contextually dependent, the authors concluded that policies should shift away from uniformly upscale innovations towards creating supportive conditions for more local specific interventions in different geographic locations.

According to Morais-da-Silva, Takahashi, and Segatto (2016), social innovations can be expanded in two distinct ways. The scaling-up strategy involves the expansion of the social innovation to other geographic regions and, therefore, reaching more of the public. On the other hand, the scaling-deep strategy relates to the ability to increase the creation of social value by either improving the service that is offered or by increasing the number of options available to the public. For the purpose of the model that is developed in this article, we only consider the scalability of social innovation in terms of the scaling-up strategy. The classification of the social innovations as local (lower spectrum of the continuum), national, regional or global (higher spectrum) is relatively simple and can be objectively measured and operationalised in the proposed model. 


\section{A categorisation scheme of social innovations}

Based on the variables that were discussed in the previous section, there are eight possible outcomes, which are represented in Figure 3 and assume special strategic meanings.

Case 1 (Figure 3(a)) includes social innovations that benefit from high policy intervention, have a high profit orientation and target a large geographical scale. This position can be considered questionable in the sense that, despite the existence of a strong emphasis on the profit orientation and a macro approach, the initiative is still highly supported by public policies. According to Millard, Weerakkody, Missi, Kapoor, and Fernando (2016), the government has a unique role in social innovation since it is the only actor that can ensure sustainability and balanced public value so that all segments of society benefit. This implies that the government should assume tradeoffs when they are seen as fair and proportionate. Classical economic theory posits that resources are scarce by nature and that most decisions face an opportunity cost in their allocation of resources. According to Sandstrom, Wennberg, Wallin, and Zherlygina (2018), policy initiatives are subject to 'deadweight' and 'displacement' effects. In the context of social innovation, 'deadweight' effects relate to the possibility of social innovation projects, which are supported by state policies, not reaching the desirable effects. 'Displacement' effects relate to the likelihood that policy initiatives favouring a specific social innovation may capture resources that could otherwise be invested in more favourable new ventures. If market mechanisms allow the promoters of the social innovation to pursue financial benefits and there is a global market for the innovation, government support may be reduced and limited to address other selected systemic failures.

The following case in the matrix (Figure 3(b)) involves a context characterised by low policy intervention, low profit orientation and low geographical scale. We consider this position as mostly reflecting an initial stage of social innovation initiatives and, because of that, it is ambiguous. According to Grimm, Fox, Baines, and Albertson (2013), most social innovations are typically bottom-up, civil society initiated and led, small scale and highly local and contextualised (at least initially). In this initial stage, policy support is probably non-existent, given that many social innovations take place below the radar and in the gaps left by the state and the market where regulation and support are uncertain. The ambition of these projects may be to transit to case 4 or case 7 , depending on the capacity of the social innovation to be self-sustainable based on the market mechanisms. In the long term, if the project is not able to make the transition, it may take on a threatened position.

An alternative route to sustain these micro-level nonprofit initiatives consists of gaining support from civil actors and local communities. Small and locally embedded social innovation initiatives, which are supported by civil actors, can address a variety of distinct needs by empowering vulnerable groups. Social innovations characterised by low policy intervention, low profit orientation and low geographical scale can be commonly observed on the African continent. According to Howaldt, Kaletka, Schröder, and Zirngiebl (2018), many social innovations in Africa are bottom-up and focus on empowering disadvantaged groups, as well as developing human resources and knowledge, without benefiting from policy support from and the involvement of public 

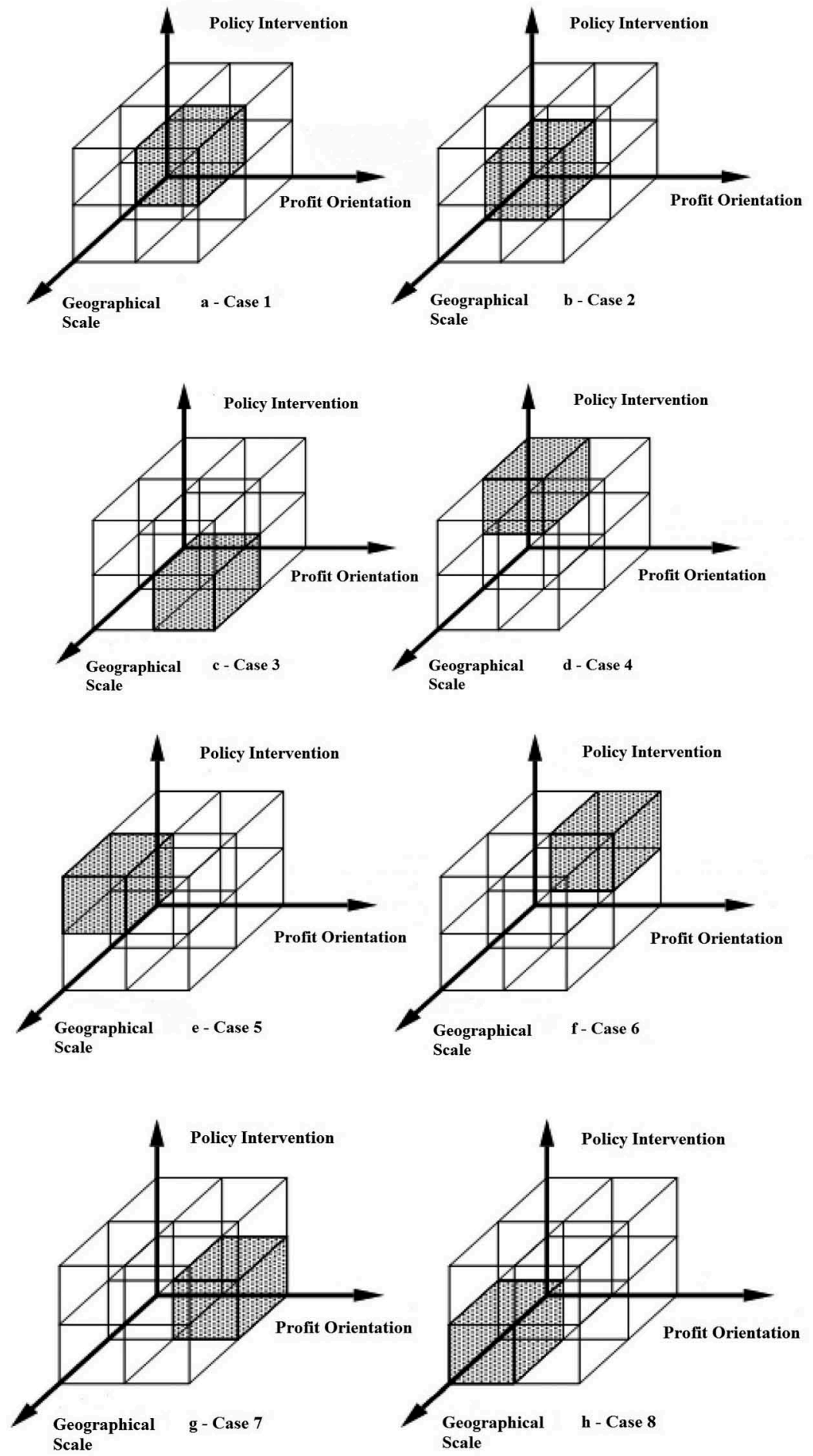

Figure 3. Categorisation of social innovation initiatives.

Source: Authors 
actors. This demonstrates the key role of civil actors in Africa and the importance of social networks and community involvement as key drivers of social innovation on the continent.

Case 3 (Figure 3(c)) reflects a position of low policy intervention, high profit orientation and high geographical scale. In this dimension, we found social innovation initiatives that are sustainable based on market mechanisms and that are also able to escalate to a macro level - and we classify this dimension as market sustained. This may include, for example, social enterprises that seek to balance social and financial value by tackling social problems through business solutions and adopting corporate social innovation. These include WaterHealth International, who provides safe water to the poor in India, the Philippines and Ghana at prices near costs (Kuratko, Mcmullen, Hornsby, \& Jackson, 2017), and the Grameen Bank, whose model of fighting poverty by bringing financial services to poor people and helping them to establish profitable businesses is profitable and was able to expand globally. Case 3 may also include for-profit global companies that prioritise financial value while also remaining committed to social value in the form of active corporate social responsibility (CSR) actions (e.g., Timberland and Patagonia). In the private sector, CSR emphasises the importance of the social dimension of businesses and provides a stimulus for companies to develop innovative solutions that combine business goals with social goals (Gallouj, Rubalcaba, Toivonen, \& Windrum, 2018). For example, by studying green CSR practices in China, Wu, Liu, Chin, and Zhu (2018) found a positive relation between green CSR and innovation performance. According to the authors, green CSR can trigger innovation by improving products, producing bestpractice technologies and developing new ways of using best-practice technologies that favour the environment and thus the macro-quality of life.

Case 4 (Figure $3(\mathrm{~d})$ ) - with its high policy intervention, low profit orientation and low geographical scale - typically involves the subset of local pure social innovations (Van der Have \& Rubalcaba, 2016). Those are subject to market failures, such as: the failure of price mechanisms; the lack of sufficient income; inadequate access to credit; market entry costs; the lack of education; gender, ethnic and/or cultural discrimination; and the lack of opportunities and information to engage meaningfully in society (Grimm et al., 2013). We classify these social innovations as market constrained. According to Pol and Ville (2009), there are weighty reasons to justify policy support to these types of social innovations since they improve social performance, entail information spillovers and may even engender future business innovations that otherwise would not happen. In this context, social policies are then devised to correct the market failures. An illustrative example of how government support may be crucial to these types of innovations is provided by d'Ovidio and Pradel (2013); the authors combine a sociological and an economic perspective to empirically analyse the institutionalisation processes of two innovative social projects that are related to the arts in the cities of Milan and Barcelona.

Hangar in Barcelona and Isola della Moda in Milan are similar social innovation projects targeting the inclusion of young artists and designers in the labour market, but they have different paths of institutionalisation due to the institutional contexts in which they are embedded and the governance models. Hangar succeeded in surviving by agreeing to an inclusive policy with the city council, thus generating a strong process of institutionalisation based on public funding. Isola della Moda, which tries to redefine 
the sector basics, was not able to engage with any public institution, nor does it have access to any of the strong private networks. While Hangar in Barcelona can be considered an example of the successful institutionalisation of a bottom-up experiment at the local level, Isola della Moda is subject to a hard process of institutionalisation due to the nature of the opposition to the established players in the system and the lack of supportive government policy.

Finally, we should mention that, independently of the arguments supporting the need for the government to back up pure social innovations, there also considerable risks involved. While the government may play a significant role in providing the economic underpinnings of social innovation, dependency on the public purse also carries risks for the sustainability of socially innovative enterprises (Grimm et al., 2013). For example, in times of crises, governments may cut funding to these projects.

A natural ambition of the projects classified in case 4 may be to geographically escalate and ascend to the dimension reflected in case 5 (Figure 3(e)). One of the main public policy goals related to social innovation is to replicate or transfer successful initiatives so that the impacts and benefits can be as widely felt as possible (Millard et al., 2016). When social innovations have the potential to benefit more people, there is a strong argument for scaling them up (Gabriel, 2014). However, some social innovations are difficult to transfer and scale due to their specificity at the local level. For example, Gordon, Becerra, and Fressoli (2017) describe how an Argentinian social innovation project (Pro-huerta), which is framed by solidary economics and consists of a top-down initiative to empower poor communities by providing small tools for farming along with seed and small farm animals, faced several difficulties in transcending its initial level and needed to be put into a perspective relative to the broader picture of agricultural policy in Argentina. Because of the large diversity of the ecological characteristics in the country, not every plant selected by the promoters of the programme worked or suited the local characteristics of the terrain. Massive transgenic agribusiness based on soybean production was another problem associated with the programme. According to Grimm et al. (2013), it is difficult to transfer good, basic ideas and practices to other organisations elsewhere, even when they are in close proximity, and this gets even harder as the geographical distance increases, given that the contextual conditions become increasingly alien.

Millard et al. (2016), using a questionnaire in the context of a European Commission study, named the SI-DRIVE research project, identify a series of challenges faced by most people and communities that are less likely to be context dependent, and, because of that, would potentially be more feasible to escalate. These include, for example, social innovations in the areas of advocacy and community building, micro-financing and safety nets, responsible local food sourcing and food waste reduction, local job matching, and peer and networked approaches to education, health and tackling disadvantages.

Case 6 (Figure 3(f)) - with its high policy intervention, high profit orientation and low geographical scale - is similar to case 1; however, the focus of the innovations is local and not global. This dimension includes both long-term profitable initiatives of social innovation that are specific to geographical contexts and lucrative social innovations that are still in an introductory stage. In this second case, and despite the profit orientation, public support may be necessary due to the liabilities of 
smallness and newness. Considering the fundamental economic principles of scarcity and rational self-maximising behaviour in the field of public policy, we consider that if these projects become self-sustainable, government authorities should ponder their level of support.

Similarly to case 3 , case 7 (Figure $3(\mathrm{~g})$ ) includes social innovation initiatives that are sustainable based on market mechanisms without government support; however, in this case, they are operationalised at a local scale. Sometimes, voluntary, self-organised groups may provide cost-effective, efficient means of addressing some of the pressing social challenges that large government institutions, agencies and businesses do not appear to be able to solve (Mongelli \& Rullani, 2017). In addition, technological developments have propelled some market-driven and bottom-up solutions, thus limiting the need for public support. For example, the creation of an online commercial offer supporting the main social mission emerges as a solution adopted by some small-scale social innovation projects (Howaldt et al., 2018).

Case 3 types of projects can aspire to escalate. However, the practice shows that immature social enterprises need to focus more on capacity development and be patient with themselves before engaging in aggressive scaling (Gramescu, 2016). The success of scaling strategies depends on a series of factors, including financial resources, leadership, the organisation's internal environment and the settings of the external environment (Morais-da-Silva et al., 2016) and how these factors interrelate. As stressed by Cajaiba-Santana (2014) in the first paper analysed in this article, agentic actions, the social structures within the organisation and the environment decisively interact in processes of social innovation and scale-up strategies. Some scaling strategies may better suit the limitations of small local projects. Whereas more mature projects can escalate based on traditional scaling strategies, such as growing an organisation to increase the delivery capacity, setting up new branches and growing the organisation's capacity and resources, smaller initiatives can alternatively opt for forming strategic partnerships or improving the delivery network through delivery contracts, communities of practice, federations and membership models.

Finally, case 8 (Figure 3(h)) consists of social innovations that require low policy intervention and have a low profit orientation and high geographical scale. This type of social innovation project is unlikely to be sustainable unless the promoters can secure stable, long-term, non-governmental mass support from sources such as patronage or philanthropy, crowdfunding or collaborative efforts. We classify these as external nongovernmental resource-dependent projects.

A successful example of this type of innovation is Bono and Bobby Shriver's Red campaign, a licensed brand that partners with private companies such as Nike, American Express and Apple to raise money to help combat AIDS in Africa (Kuratko et al., 2017). Another example includes projects that rely on collaborative efforts, such as the digital Open Source movement. Numerous applications, including Mozilla, Open-Office, Wikipedia and Linux, were developed collaboratively by the open source community of programmers and volunteers (Grimm et al., 2013) and reflect an effort to make these tools available for more fragile groups of society. Inclusive technological innovation ('technology for poor'), such as the 'open source movement', is often presented as an example of social innovation because social goals play a central role 
in them (Gallouj et al., 2018), including bridging the digital divide between people with more and fewer resources.

\section{Conclusions}

This article adopts an integrative approach to address the complexity of the social innovation concept by analysing and comparing distinct approaches to social innovation and proposing a categorisation scheme of social innovation initiatives.

Cajaiba-Santana (2014) presents a sociologically inspired framework of social innovation that combines an institutional perspective with a structuration perspective. In the institutional perspective, social innovation is framed as a result of knowledge and resource exchanges between actors that are mobilised through legitimisation activities. Meanwhile, from a structuration perspective, social innovation is socially constructed as individuals collectively engage in purposeful actions and reflexively monitor the outcomes of their actions. Despite the attempted comprehensive nature of the model, we found it to lack important dimensions that are usually captured in more economic conceptualisations of social innovation, including the antecedents that may force or favour social innovation processes and the outcomes of the processes. The sociologically oriented framework of social innovation proposed by Cajaiba-Santana (2014) contrasts with the economic conceptualisation adopted by Pol and Ville (2009) who, after exploring the differences between business and social innovation, present a very straightforward outcome-oriented definition of desirable social innovation: innovation that improves either the macro-quality or the quantity of life.

Finally, we presented a literature-informed categorisation scheme of social innovations based on three key variables: the level of policy support, the profit orientation and the geographical scale. Based on the analysis of the implied dimensions, we highlighted which types of social innovations can potentially require governmental support, the conditions associated with scaling social innovations and the risks involved in both cases.

In this article, we adopted Van der Have and Rubalcaba's (2016) approach by considering that, parallel to societal good, it is possible for social innovations to pursue profit objectives. This approach is at odds with alternative views that push for a concept of social innovation that totally excludes the objective of profit maximisation (CajaibaSantana, 2014; Gregoire, 2016). Different understandings of social innovation can also be observed in some organisations that promote social innovation. For example, while the Young Foundation and Nesta differentiate social innovation from business innovation by claiming that social innovation should not seek profit maximisation (as in business innovation), the European Union correlates social innovation with economic growth, thus implying an economic view of the phenomenon (Fougère, Segercrantz, \& Seeck, 2017). In line with Pol and Ville (2009), we concluded that policy efforts should privilege the support of social innovation initiatives that, while having the potential to deliver social good, are subject to market failures. In addition, we also argue in favour of government support for small bottom-up initiatives that have a profit-logic but are not sufficiently robust to survive on their own due to the liabilities of smallness and 
newness. Finally, we advised caution in public policies supporting scale-up strategies and highlighted the inherent challenges.

Some critics of the 'economic approach' to social innovation criticise its neo-liberal logic by arguing against its win-win fantasy, the fast-policy emphasis and the core idea that social innovation needs to contribute to economic growth (Fougère et al., 2017). Others criticise how the neo-liberal political discourse used the term social innovation to legitimise investments in the third and private sectors in order to retrench the welfare state by considering that grassroots initiatives are a superior mechanism to deliver welfare (Goldsmith, Georges, \& Burke, 2010). Rogelja, Ludvig, Weiss, and Secco (2018) consider that in developed economies social innovation concepts and policies tend to emphasise the economic features of social innovation rather than the social dimension by prioritising social business enterprises over social movements. The growing popularity of some hybrid social/for-profit business structures (such as benefit corporations in the US, and community interest companies in the UK) and the development of specific investment funds that attract private capital (Satalkina \& Shpak, 2018) seem to confirm this tendency.

A higher emphasis in social movements can be found in some Latin American countries, such as Argentina, Brazil, Ecuador, Mexico, Colombia and Peru, in which the notion of the solidarity-based economy encompasses differentiated types of social actors (unions, universities, the government, the private sector, the church, international cooperation, organised civil society and popular civic movements) participating in processes of social transformation (Dávila, Vargas, Blanco, Cáceres, \& Vargas, 2018). Based on the principles of social inclusion, the strengthening of endogenous capacities, participatory decision making, and collective and community work, the solidarity-based economy constitutes a non-capitalist alternative paradigm of socioeconomical organisation that has been linked with the notion of social innovation because of its emphasis on social objectives and innovative forms of business organisation based on self-management and collective ownership (Anglada, 2016). Governments should realise that the pathways for social innovations are non-linear and that social innovation can arise in many forms. The social innovation concept advanced by Pol and Ville (2009) has the advantage of covering a large spectrum of social innovation manifestations and being suitable for different political contexts.

Our model also has implied the notion that governments should ponder their support for social innovation initiatives based on the analysis of specific outputs, including profit and the geographical scale (understood in this work as a proxy for the social impact generated by the projects of social innovation). However, some critics of the neo-liberal approach oppose the very notion of output analysis of social innovation as 'contributing to the further systematisation of calculus as basis for action' (Fougère et al., 2017, p. 28). Independently of the ideological discussion, profitable social innovations are potentially more sustainable in the long run and less dependent on government support. Conversely, governments need to ponder their decisions by considering the possible trade-offs and the limitations of scarce/limited public resources. In fact, some authors recognise how the lack of quantifiable information regarding the solidarity-based economy causes problems for policy decision makers in Latin American countries (e.g., Anglada, 2016; Dávila et al., 2018).

The two streams of economic and sociological approaches to the concept of social innovation hardly ever communicate, further contributing to the divide and the 
'fuzziness' of the concept. Being based on distinct ideological approaches, this article adopts an integrative approach to address the complexity of the social innovation concept and proposes a straightforward categorisation scheme of social innovation initiatives as an instrument to reflect upon public policies. In its simplicity, the proposed scheme is designed to be suitable for various contexts and application fields. Nevertheless, it is based on the core principles of market-based economies and recognises the importance of public policy for social innovation.

\section{Disclosure statement}

No potential conflict of interest was reported by the authors.

\section{ORCID}

Nuno Baptista (D) http://orcid.org/0000-0001-7130-0543

António Carrizo Moreira (iD) http://orcid.org/0000-0002-6613-8796

\section{References}

Adams, D., \& Hess, M. (2010). Social innovation and why it has policy significance. The Economic and Labour Relations Review, 21(2), 139-156.

Anglada, S. E. (2016). De la innovación social a la economía solidaria. Claves prácticas para el desarrollo de políticas públicas. [From social innovation to the solidary economy. Practical orientations for public policies.]. CIRIEC-España, Revista de Economía Pública, Social $y$ Cooperativa, 88, 201-230.

Borzaga, C., \& Bodini, R. (2014). What to make of social innovation? Towards a framework for policy development. Social Policy and Society, 13(3), 411-421.

Cajaiba-Santana, G. (2014). Social innovation: Moving the field forward. A conceptual framework. Technological Forecasting and Social Change, 82(1), 42-51.

d'Ovidio, M., \& Pradel, M. (2013). Social innovation and institutionalisation in the cognitive-cultural economy: Two contrasting experiences from Southern Europe. Cities, 33, 69-76.

Dávila, R., Vargas, A., Blanco, L., Cáceres, L. E., \& Vargas, L. A. (2018). Características de la economía solidaria colombiana. Aproximaciones a las corrientes influyentes en Colombia. [Characteristics of the Colombian solidarity economy. Approaches to influential currents in Colombia.]. CIRIEC-España, Revista de Economía Pública, Social y Cooperativa, 93, 85-113.

Dawson, P. M., \& Daniel, L. (2010). Understanding social innovation: A provisional framework. International Journal of Technology Management, 51(1), 9-21.

Dembek, K., Singh, P., \& Bhakoo, V. (2016). Literature review of shared value: A theoretical concept or a management buzzword? Journal of Business Ethics, 137(2), 231-267.

Edwards-Schachter, M., \& Wallace, M. L. (2015). 'Shaken, but not stirred ': Six decades defining social innovation. INGENIO Working Paper Series, (2015-04), 1-39.

Fougère, M., Segercrantz, B., \& Seeck, H. (2017). A critical reading of the European Union's social innovation policy discourse: (Re)legitimizing neoliberalism. Organization, 24(6), 819-843.

Furmanska-Maruszak, A., \& Sudolska, A. (2016). Social innovations in companies and in social economy enterprises. Comparative Economic Research, 19(3), 169-191.

Gabriel, M. (2014). Making it big: Strategies for scaling social innovations. London, UK: NESTA. Retrieved from https://www.nesta.org.uk/report/making-it-big-strategies-for-scaling-socialinnovations/ 
Gallouj, F., Rubalcaba, L., Toivonen, M., \& Windrum, P. (2018). Understanding social innovation in services industries. Industry and Innovation, 25(6), 551-569.

Goldsmith, S., Georges, G., \& Burke, T. G. (2010). The power of social innovation: How civic entrepreneurs ignite community networks for good. Oxford, Great Britain: John Wiley \& Sons.

Gordon, A., Becerra, L. D., \& Fressoli, M. (2017). Potentialities and constraints in the relation between social innovation and public policies: Some lessons from South America. Ecology and Society, 22(4), 1-7.

Gramescu, L. (2016). Scaling social innovation in Europe : An overview of social enterprise readiness. Procedia - Social and Behavioral Sciences, 221, 218-225.

Gregoire, M. (2016). Exploring various approaches of social innovation: A francophone literature review and a proposal of innovation typology. Mackenzie Management Review, 17(6), 45-71.

Grimm, R., Fox, C., Baines, S., \& Albertson, K. (2013). Social innovation, an answer to contemporary societal challenges? Locating the concept in theory and practice. Innovation: the European Journal of Social Science Research, 26(4), 436-455.

Hiteva, R., \& Sovacool, B. (2017). Harnessing social innovation for energy justice: A business model perspective. Energy Policy, 107, 631-639.

Howaldt, J., Kaletka, C., Schröder, A., \& Zirngiebl, M. (2018). Atlas of social innovation. New practices for a better future. Dortmund: Dortmund University. Retrieved from www.socialin novationatlas.net

Kuratko, D. F., Mcmullen, J. S., Hornsby, J. S., \& Jackson, C. (2017). Is your organization conducive to the continuous creation of social value? Toward a social corporate entrepreneurship scale. Business Horizons, 60(3), 271-283.

Le Grand, J. (1991). The theory of government failure. British Journal of Political Science, 21(04), 423.

Millard, J., Weerakkody, V., Missi, F., Kapoor, K., \& Fernando, G. (2016). Social innovation for poverty reduction and sustainable development: Some governance and policy perspectives. In ACM (Ed.), 9th International Conference on Theory and Practice of Electronic Governance (pp. 153-162). Uruguay: Montevideo.

Mongelli, L., \& Rullani, F. (2017). Inequality and marginalisation: Social innovation, social entrepreneurship and business model innovation. Industry and Innovation, 24(5), 446-467.

Morais-da-Silva, R. L., Takahashi, R. A., \& Segatto, A. P. (2016). Scaling up social innovation: A meta-synthesis. Mackenzie Management Review, 17(6), 134-163.

Neumeier, S. (2012). Why do social innovations in rural development matter and should they be considered more seriously in rural development research? - Proposal for a stronger focus on social innovations in rural development research. Sociologia Ruralis, 52(1), 48-69.

Nicholls, A., \& Murdock, A. (2012). The Nature of Social Innovation. In A. Nicholls \& A. Murdock (Eds.), Social innovation. Blurring boundaries to reconfigure markets (pp. 1-30). Basingstoke, UK: Palgrave Macmillan UK.

Păunescu, C. (2014). Current trends in social innovation research: Social capital, corporate social responsibility, impact measurement. Management and Marketing, 9(2), 103-116.

Pol, E., \& Ville, S. (2009). Social innovation: Buzz word or enduring term? The Journal of SocioEconomics, 38(6), 878-885.

Rana, N. P., Weerakkody, V., Dwivedi, Y. K., \& Piercy, N. C. (2014). Profiling existing research on social innovation in the public sector. Information Systems Management, 31(3), 259-273.

Rogelja, T., Ludvig, A., Weiss, G., \& Secco, L. (2018). Implications of policy framework conditions for the development of forestry-based social innovation initiatives in Slovenia. Forest Policy and Economics, 95, 147-155.

Sandstrom, C., Wennberg, K., Wallin, M. W., \& Zherlygina, Y. (2018). Public policy for academic entrepreneurship initiatives: A review and critical discussion. Journal of Technology Transfer, 43, 1232-1256.

Satalkina, L., \& Shpak, N. (2018). Evaluation of the influence of the macro-environment on the social innovation activity of enterprises. Organizacija, 51(1), 36-48. 
Schumpeter, J. A. (1949). Economic theory and entrepreneurial history - Change and the entrepreneur, postulates and patterns for entrepreneurial history. Cambridge: Harvard University Press, Ed.

Tamm, D. (2010). System failures in public sector innovation support measures : The case of Estonian innovation system and dairy industry (Discourses in Social Market Economy No. 2010-07). Retrieved from https://ideas.repec.org/p/zbw/opodis/201007.html

Van der Have, R. P., \& Rubalcaba, L. (2016). Social innovation research: An emerging area of innovation studies? Research Policy, 45(9), 1923-1935.

Weber, K. M., \& Rohracher, H. (2012). Legitimizing research, technology and innovation policies for transformative change Combining insights from innovation systems and multi-level perspective in a comprehensive 'failures' framework. Research Policy, 41(6), 1037-1047.

Westley, F., Antadze, N., Riddell, D. J., Robinson, K., \& Geobey, S. (2014). Five configurations for scaling up social innovation case examples of nonprofit organizations from Canada. The Journal of Applied Behavioral Science, 50(3), 234-260.

Wu, W., Liu, Y., Chin, T., \& Zhu, W. (2018). Will green CSR enhance innovation? A perspective of public visibility and firm transparency. International Journal of Environmental Research and Public Health, 15(2), 1-14. 